\title{
Impact of Interpersonal Problems in Borderline Personality Disorder Inpatients on Treatment Outcome and Psychopathology
}

\author{
Gerhard Dammann $^{\mathrm{a}, \mathrm{b}, \mathrm{d}} \quad$ Anke Riemenschneider $^{\mathrm{a}}$ Marc Walter $^{\mathrm{a}}$

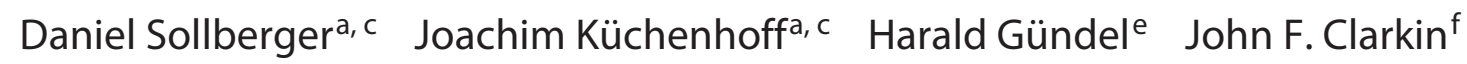 \\ Daniela J. Gremaud-Heitz ${ }^{\mathrm{a}, \mathrm{b}}$ \\ a Psychiatric Hospital, University of Basel, Basel, b Psychiatric Hospital, Münsterlingen, and 'Psychiatric Hospital, \\ Liestal, Switzerland; dParacelsus Medical University, Salzburg, Austria; ${ }^{\mathrm{e} D e p a r t m e n t}$ of Psychosomatic Medicine,

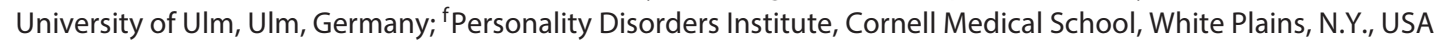

\section{Key Words}

Borderline personality disorder · Interpersonal problems . Transference-focused psychotherapy · Treatment outcome . Identity diffusion $\cdot$ Inpatient treatment

\section{Abstract}

Background: Borderline personality disorder (BPD) is a very common illness; interpersonal problems are one of the core features. The purpose of this study was to investigate the changes in interpersonal problems after transference-focused psychotherapy (TFP)-based disorder-specific treatment and to explore whether the severity of interpersonal problems could serve as a predictor for other variables. Sampling and Methods: A sample of 37 inpatients with BPD was assessed with the Structured Clinical Interviews for DSM-IV Axis I and II Disorders (SCID I and II) and had to complete a questionnaire including the Inventory of Interpersonal Problems (IIP-C), Inventory of Personality Organization (IPO), Beck Depression Inventory (BDI), Spielberger State and Trait Inventory (STAI), Spielberger State and Trait Anger Inventory
}

(STAXI), and Symptom Checklist-90 (SCL-90-R). After 12 weeks of TFP-based disorder-specific treatment, the patients repeated the same questionnaire; 7 patients had to be excluded from the study, and thus calculations were conducted with 30 patients. Results: After treatment, the patients showed a significant decrease in the IIP total item score and all 8 subscales except the domineering, intrusive, and cold scales. The IIP total item baseline score was correlated with borderline symptomatic and psychopathology [e.g. anxiety, Global Severity Index (GSI)] after 12 weeks as well as with most IIP postsubscales. Conclusions: Although interpersonal problems are considered one of the more stable features of BPD, our results showed a significant improvement after 12 weeks of TFP-based disorder-specific inpatient treatment, especially in the total score and the subscales on the friendly submissive level. The severity of interpersonal problems at baseline was connected to outcome values of other borderline features as well as general psychiatric complaints. It therefore seems important to consider the treatment of interpersonal problems in therapy to be of greater significance.

\section{KARGER}

E-Mail karger@karger.com

www.karger.com/psp
(C) 2016 S. Karger AG, Basel

0254-4962/16/0493-0172\$39.50/0
Dr. phil. Daniela J. Gremaud-Heitz Psychiatric Hospital Münsterlingen Postfach 154

CH-8596 Münsterlingen (Switzerland)

E-Mail daniela.gremaud@ stgag.ch 


\section{Introduction}

Borderline personality disorder (BPD) is one of the most common personality disorders, affecting about $0.5-$ $5.9 \%$ of the general population, around $10 \%$ of psychiatric outpatients, and $15-20 \%$ of psychiatric inpatients $[1,2]$. Its main characteristics include interpersonal problems, affective instability, disturbed identity, and impulsivity.

It is widely accepted that interpersonal problems are a central area of difficulty for those with BPD. Individuals with BPD often report greater problems with interpersonal functioning compared to healthy controls [3]. Additionally, some of the most serious outcomes related to $\mathrm{BPD}$, such as self-injury and suicide, frequently occur in interpersonal contexts [4] and are related to problems with social adjustment [5].

In the DSM-5 [6] interpersonal problems are described as a pattern of unstable and intense interpersonal relationships characterized by alternation between extremes of idealization and devaluation as well as frantic efforts to avoid real or imagined abandonment. The new DSM-5 section III model of personality disorders [6] defines interpersonal functioning, in agreement with Otto F. Kernberg's theory of structural personality organization, as the capacity for empathy and intimacy, with four severity levels of dysfunction.

Interpersonal problems are usually a central focus of treatment, enduring even after other symptoms have remitted [7, 8]. In the Collaborative Longitudinal Personality Disorders Study [9], researching the 10-year course of $\mathrm{BPD}$, all BPD criteria declined at similar rates, with affective instability having the highest rate at baseline and after 10 years. The McLean Study of Adult Development [8], on the other hand, found different courses for several BPD symptoms: after 2 years, most interpersonal symptoms were still found in $80 \%$ of the patients, whereas especially impulsive features diminished substantially, and after 10 years, interpersonal symptoms still remained present in about a quarter of the patients.

In 2009, the National Institute for Health and Clinical Excellence (NICE) [10] clinical guidelines for BPD recommended that 'when providing psychological treatment for people with BPD, especially those with multiple comorbidities and/or severe impairment, the following service characteristics should be in place: an explicit and integrated theoretical approach used by both the treatment team and the therapist, which is shared with the service user, structured care in accordance with this guideline and provision for therapist supervision' (pp. 207,208 ). Drug treatment should not be used specifically

Impact of Interpersonal Problems in BPD for BPD but may be considered in the overall treatment of comorbid conditions [10].

In the last 2 decades, several specialized BPD treatment models have been developed, in particular dialectical behavior therapy (DBT) [11], transference-focused psychotherapy (TFP) [7], mentalization-based therapy (MBT) [12], and schema-focused therapy (SFT) [13], and their efficacy has been studied [14-17].

Considering the Cochrane Review for randomized clinical trials on psychotherapy for BPD [18], there was only one study mentioned with inpatients, and this study focused on patients with posttraumatic stress disorder, with BPD only as a comorbid disorder. There was one study [12] analyzing BPD patients with MBT-oriented partial hospitalization. Compared to BPD patients treated with standard psychiatric care they showed a significant decrease in all measures, whereas the scores in interpersonal problems even increased slightly for the control group.

All other studies mentioned in the review were conducted with outpatients showing favorable effects on interpersonal problems for specialized BPD treatments: DBT [19], MBT [20], SFT group intervention [21], and specific trainings such as STEPPS (Systems Training for Emotional Predictability and Problem Solving) [22]. As for TFP, there was one study showing superiority for TFP compared to treatment by a community psychotherapist [23]. However, there was no special attention on the interpersonal aspect in this study.

To date, the literature on inpatient treatment for BPD is based largely on expert opinion. Several experts have not only dismissed the therapeutic impact that nonspecialist hospitalization has on BPD but have gone as far as suggesting that inpatient admission actually has a negative outcome $[24,25]$. Despite this being an intuitive argument, other experts have cautioned against this assumption as there is no conclusive evidence to suggest that hospitalization is harmful [26].

There was another inpatient study, controlled but not randomized [27], examining the effectiveness of a 3-month inpatient DBT. Compared to patients on the waiting list (with outpatient care), patients improved significantly more in most variables as well as in interpersonal functioning. The degree of change over the 3-month period was predicted by the initial scores: prevalues correlated positively with subsequent improvement [27]. In a more recent study, Leichsenring et al. [28] compared psychoanalytic-interactional therapy to psychodynamic therapy in inpatients with Cluster B personality disorder and found a significant reduction in interpersonal problems in both treatment groups. 
As one can see, studies on inpatient treatment for BPD are sparse. To our knowledge, until now there is no study that investigated the effects of a disorder-specific BPD treatment which combines DBT and TFP modules, and virtually no study considering interpersonal problems included interpersonal subscales.

The aim of our study was to examine the effect of a TFPbased disorder-specific inpatient treatment on interpersonal problems in patients with BPD. Another question was whether interpersonal problems could serve as a predictor for other borderline or psychopathological features.

\section{Methods}

Study Design and Participants

All patients were inpatients at the Psychiatric Hospital of the University of Basel and were diagnosed with BPD according to the DSM-IV-TR criteria. Patients participated in an inpatient study for BPD patients (Basel Borderline Inpatient Study, BABIS). The aims of the BABIS were to analyze the effects of a specialized borderline treatment and to identify the possible influence of subgroups within the heterogeneous group of BPD patients. Detailed descriptions of the aims, methods, and sample characteristics [29, $30]$ of the BABIS have been reported separately. Previously published results showed amongst other things that comorbid atypical depression in BPD patients was correlated with psychopathology, anxiety, and interpersonal problems [31] and that patients with higher identity diffusion also showed higher levels of psychiatric symptoms such as anxiety anger and depression [32].

Patients were treated at a specialized psychotherapeutic unit with a set stay length of 12 weeks. They received a disorder-specific treatment that combines a psychodynamic TFP approach with DBT skill training modules. TFP tries to change the patients' concepts of self and significant others and to treat interpersonal disturbances by focusing on patients' transference relationships and interactions with other patients during the inpatient treatment. The treatment combined twice-weekly individual TFP sessions (in accordance with the TFP treatment manual of Clarkin et al. [33]) with a primary therapist trained in TFP together with twice-weekly TFP-oriented psychodynamic group therapy with nurses and a social worker; in addition, the therapists had weekly supervision and consultation meetings. In addition, and depending on the demonstrated improvements in affect regulation [16], patients in the disorder-specific treatment unit attended weekly DBT-based skill training groups conducted by trained staff nurses to augment the TFP treatment. Whereas DBT skill sessions focus particularly on mindfulness and on coping with extreme affect states and dysfunctional behavior, TFP targets the conflicts amongst the patient's internal representations of self and others within the transference and interpersonal problems [34].

Exclusion criteria were schizophrenia, schizoaffective disorder, active psychosis, or acute manic episode. Written informed consent was obtained from each patient. The study was approved by the local ethics committee (EKBB). The assessment point was the first week after entering the clinic. Posttesting was conducted 12 weeks after the initial assessment.
Table 1. Demographic and clinical characteristics of patients with $\operatorname{BPD}(\mathrm{n}=30)$

\begin{tabular}{|c|c|}
\hline Age $($ mean $\pm S D)$, years & $26.4 \pm 6.1$ \\
\hline \multicolumn{2}{|l|}{ Gender, $\mathrm{n}(\%)$} \\
\hline Male & $5(16.7)$ \\
\hline Female & $25(83.3)$ \\
\hline \multicolumn{2}{|l|}{ Marital status, $\mathrm{n}(\%)$} \\
\hline Living alone & $23(76.7)$ \\
\hline Living with a partner & $7(23.3)$ \\
\hline \multicolumn{2}{|l|}{ Current employment, $\mathrm{n}(\%)$} \\
\hline Employed (full/part time)/apprenticeship & $18(60)$ \\
\hline Unemployed/disability pension & $12(40)$ \\
\hline \multicolumn{2}{|l|}{ Years of education, $\mathrm{n}(\%)$} \\
\hline$<9$ years & $11(36.7)$ \\
\hline $9-12$ years & $13(43.3)$ \\
\hline$>12$ years & $6(20)$ \\
\hline \multicolumn{2}{|l|}{ Duration of illness, $\mathrm{n}(\%)$} \\
\hline$<1$ year & $1(3.3)$ \\
\hline $1-5$ years & $13(43.3)$ \\
\hline $5-10$ years & $4(13.3)$ \\
\hline $10-20$ years & $8(26.7)$ \\
\hline$>20$ years & $4(13.3)$ \\
\hline \multicolumn{2}{|l|}{ Comorbid Axis I disorder, $\mathrm{n}(\%)$} \\
\hline None & $2(6.7)$ \\
\hline Affective disorder & $25(83.3)$ \\
\hline Anxiety disorder & $18(60)$ \\
\hline Substance-related disorder & $17(56.7)$ \\
\hline Eating disorder & $13(43.3)$ \\
\hline \multicolumn{2}{|l|}{ Comorbid Axis II disorder, $\mathrm{n}(\%)$} \\
\hline None & $8(26.7)$ \\
\hline Cluster A & $6(20)$ \\
\hline Cluster B & $2(6.7)$ \\
\hline Cluster C & $20(66.7)$ \\
\hline
\end{tabular}

SD = Standard deviation

\section{Interviews}

Clinically experienced interviewers received instruction on the Structured Clinical Interview for DSM-IV Axis I Disorders (SCIDI/P) [35] and for DSM-IV Axis II Disorders (SCID-II) [36] and were trained to pay particular attention to distinguishing Axis I mental state conditions from Axis II personality trait phenomena. The SCID I and II are semistructured interviews for assessing clinical and personality disorders. Good interrater reliability (SCID I mean $\kappa=0.71$; SCID II mean $\kappa=0.84$ ) has been shown for both interviews [37].

\section{Questionnaire Data}

For the evaluation of interpersonal criteria, we used the German version of the Inventory of Interpersonal Problems (IIP) [38], a 64-item self-report instrument designed to measure interpersonal deficiencies and excesses in 8 subscales (e.g. too responsible, too controlling) and a general scale. The IIP is based on a two-dimensional circular model of interpersonal dysfunction with two axes (domineering vs. nonassertive and self-sacrificing vs. cold). The validity and reliability of the IIP has been demonstrated [33]. 
Table 2. Pre-post tests of all patients

\begin{tabular}{|c|c|c|c|c|c|c|c|}
\hline Variable & Mean-pre & SD-pre & Mean-post & SD-post & $\mathrm{t}$ & $\mathrm{p}$ & $\mathrm{d}$ \\
\hline \multicolumn{8}{|l|}{ IIP } \\
\hline Total score & 1.86 & 0.48 & 1.66 & 0.47 & 3.10 & $0.004^{* *}$ & 0.421 \\
\hline Domineering & 6.30 & 4.42 & 7.03 & 4.91 & -1.21 & 0.235 & 0.156 \\
\hline Vindictive & 10.20 & 5.02 & 8.67 & 4.69 & 2.13 & $0.042 *$ & 0.315 \\
\hline Cold & 12.97 & 5.49 & 12.20 & 5.01 & 0.78 & 0.443 & 0.147 \\
\hline Socially inhibited & 18.33 & 6.35 & 16.20 & 5.49 & 2.26 & $0.031^{*}$ & 0.359 \\
\hline Nonassertive & 18.93 & 8.29 & 16.60 & 7.92 & 3.30 & $0.003^{* *}$ & 0.287 \\
\hline Overly accommodating & 17.97 & 6.93 & 15.73 & 6.82 & 2.35 & $0.026^{*}$ & 0.326 \\
\hline Self-sacrificing & 21.12 & 6.37 & 17.75 & 5.93 & 4.46 & $0.000^{* *}$ & 0.548 \\
\hline Intrusive & 13.47 & 5.09 & 12.23 & 4.56 & 1.84 & 0.077 & 0.257 \\
\hline \multicolumn{8}{|l|}{ IPO } \\
\hline Identity diffusion & 62.57 & 12.90 & 58.27 & 14.20 & 2.91 & $0.007^{* *}$ & 0.317 \\
\hline Primitive defenses & 43.06 & 8.80 & 41.82 & 10.81 & 1.00 & 0.324 & 0.126 \\
\hline Reality testing & 40.41 & 12.51 & 39.51 & 13.97 & 0.63 & 0.536 & 0.068 \\
\hline Aggression & 33.81 & 8.12 & 33.09 & 8.08 & 0.71 & 0.481 & 0.089 \\
\hline Moral values & 25.20 & 7.58 & 24.46 & 6.70 & 0.75 & 0.461 & 0.103 \\
\hline BDI & 27.44 & 9.15 & 21.68 & 12.21 & 3.46 & $0.002^{* *}$ & 0.534 \\
\hline \multicolumn{8}{|l|}{ STAI } \\
\hline State anxiety & 57.14 & 10.38 & 54.01 & 12.36 & 1.26 & 0.216 & 0.274 \\
\hline Trait anxiety & 59.05 & 8.20 & 57.34 & 9.79 & 1.29 & 0.204 & 0.189 \\
\hline \multicolumn{8}{|l|}{ STAXI } \\
\hline State anger & 18.27 & 7.45 & 14.53 & 5.34 & 3.35 & $0.002^{* *}$ & 0.577 \\
\hline Trait anger & 22.13 & 7.48 & 20.42 & 6.36 & 1.94 & 0.062 & 0.246 \\
\hline \multicolumn{8}{|l|}{ SCL-90 } \\
\hline GSI & 1.48 & 0.60 & 1.37 & 0.67 & 1.16 & 0.255 & 0.173 \\
\hline Somatization & 1.03 & 0.62 & 0.94 & 0.68 & 0.88 & 0.386 & 0.138 \\
\hline Obsessive-compulsive & 1.55 & 0.62 & 1.58 & 0.86 & -0.17 & 0.863 & 0.040 \\
\hline Interpersonal sensitivity & 1.83 & 0.82 & 1.73 & 0.78 & 0.85 & 0.403 & 0.125 \\
\hline Depression & 2.11 & 0.78 & 1.90 & 0.86 & 1.49 & 0.147 & 0.256 \\
\hline Anxiety & 1.48 & 0.73 & 1.48 & 0.76 & 0.71 & 0.482 & 0.000 \\
\hline Hostility & 1.33 & 0.92 & 1.40 & 1.04 & 0.50 & 0.625 & 0.071 \\
\hline Phobic anxiety & 1.38 & 1.03 & 1.26 & 0.89 & 1.49 & 0.146 & 0.125 \\
\hline Paranoid ideation & 1.29 & 0.86 & 1.13 & 0.95 & -0.15 & 0.886 & 0.177 \\
\hline Psychoticism & 1.09 & 0.67 & 0.96 & 0.78 & 1.39 & 0.176 & 0.179 \\
\hline
\end{tabular}

$\mathrm{SD}=$ Standard deviation. ${ }^{*} \mathrm{p}<0.05 ; * * \mathrm{p}<0.01$

To assess other borderline features, the Inventory of Personality Organization (IPO) $[39,40]$ was used. The scales of the IPO measure the constructs of identity diffusion, primitive defenses, reality testing, aggression, and moral values. Good validity and reliability have consistently been demonstrated for the IPO [41].

To measure the general psychiatric symptoms and subjective complaints, we administered the German versions of the Symptom Checklist-90 (SCL-90-R) [42], Beck Depression Inventory (BDI) [43], Spielberger State and Trait Inventory (STAI) [44], and Spielberger State and Trait Anger Inventory (STAXI) [45].

\section{Statistical Analyses}

All statistical analyses were conducted with SPSS/20.0. Assumption of homoscedasticity and normality distribution was checked prior to the analysis. For comparison before and after treatment, we ran a paired $t$ test (normal-distributed data) and the Wilcoxon signed-rank test (no normal distribution assumed), respectively. Correlations were conducted with the Pearson (normal-distributed data) or Spearman (no normal distribution assumed) correlation. All test results were considered significant at a two-sided level of $\mathrm{p}<0.05$.

\section{Results}

A total of 37 patients diagnosed with BPD were included in the study and interviewed (5 patients did not complete the questionnaire and were therefore excluded; 2 patients did not finish the second part of our study and 


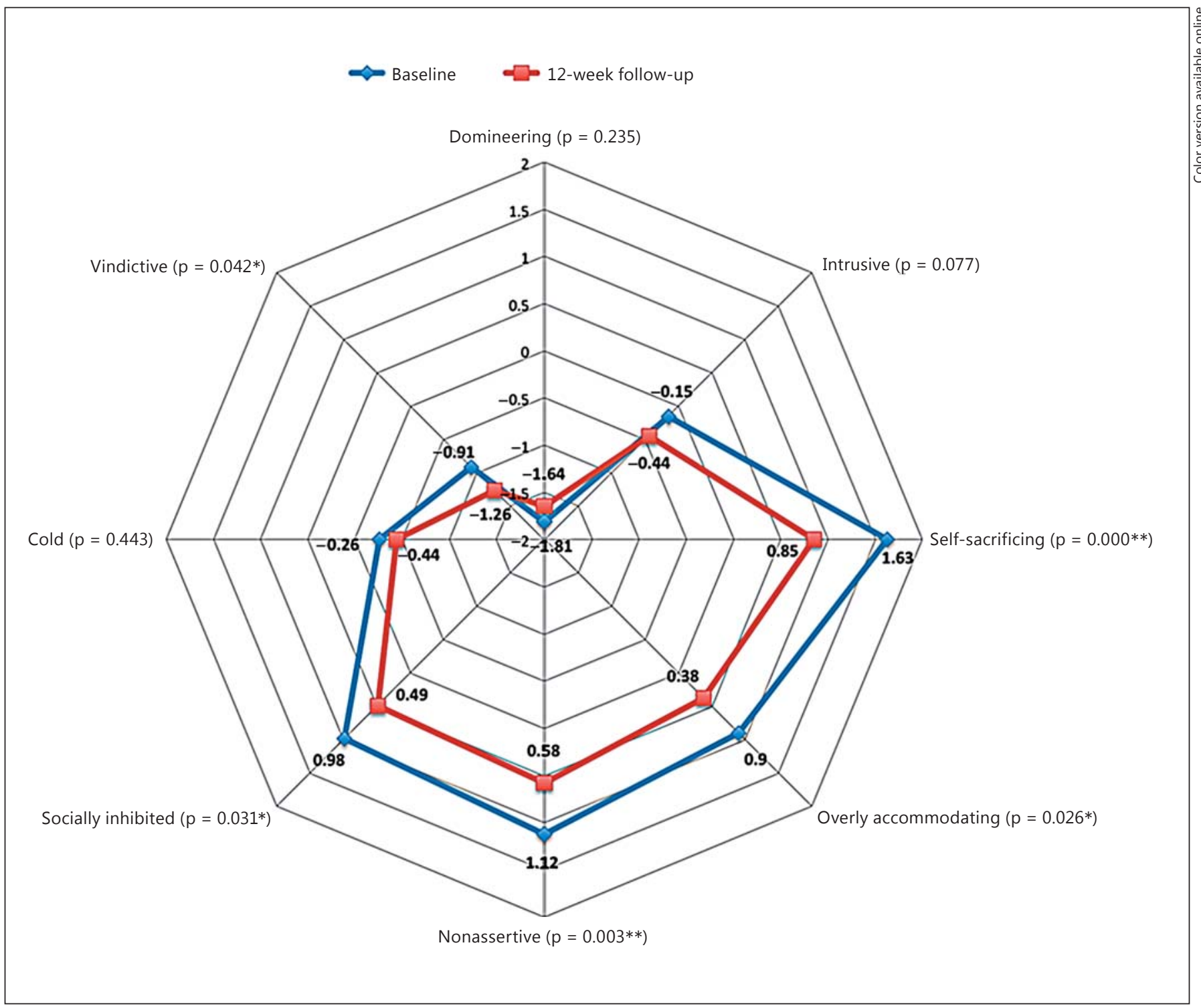

Fig. 1. Circumplex model of the IIP interpersonal subscale at baseline and after 12 weeks of inpatient treatment (z-scores), with $\mathrm{p}$ values for change. ${ }^{*} \mathrm{p}<0.05 ;{ }^{* *} \mathrm{p}<0.01$.

were also excluded). Of the 30 patients included in the study, $25(83.3 \%)$ were female and $5(16.7 \%)$ male. The mean age was 26.4 years $(\mathrm{SD}=6.1$; table 1$) .28$ patients (93.3\%) were diagnosed with a comorbid Axis I disorder, most frequently with an affective disorder $(n=25,83.3 \%)$; anxiety disorders were diagnosed in 18 patients (60\%). 22 patients (73.3\%) showed a comorbid Axis II disorder, predominantly a Cluster C disorder $(n=20,66.7 \%)$.

\section{Interpersonal Problems}

The mean value of the IIP total item score was rather high: 1.84 compared to 1.28 in the general population [38]. We therefore can assume that the degree of interpersonal problems in these patients was substantial.

\section{Pre-Post Tests of All Patients}

After treatment, patients showed a significant decrease in the IIP total item score and all subscales except the domineering, cold, and intrusive scales (table 2). There 
Table 3. Correlation of the IIP global item score at baseline after 12 weeks of inpatient treatment with other posttreatment variables

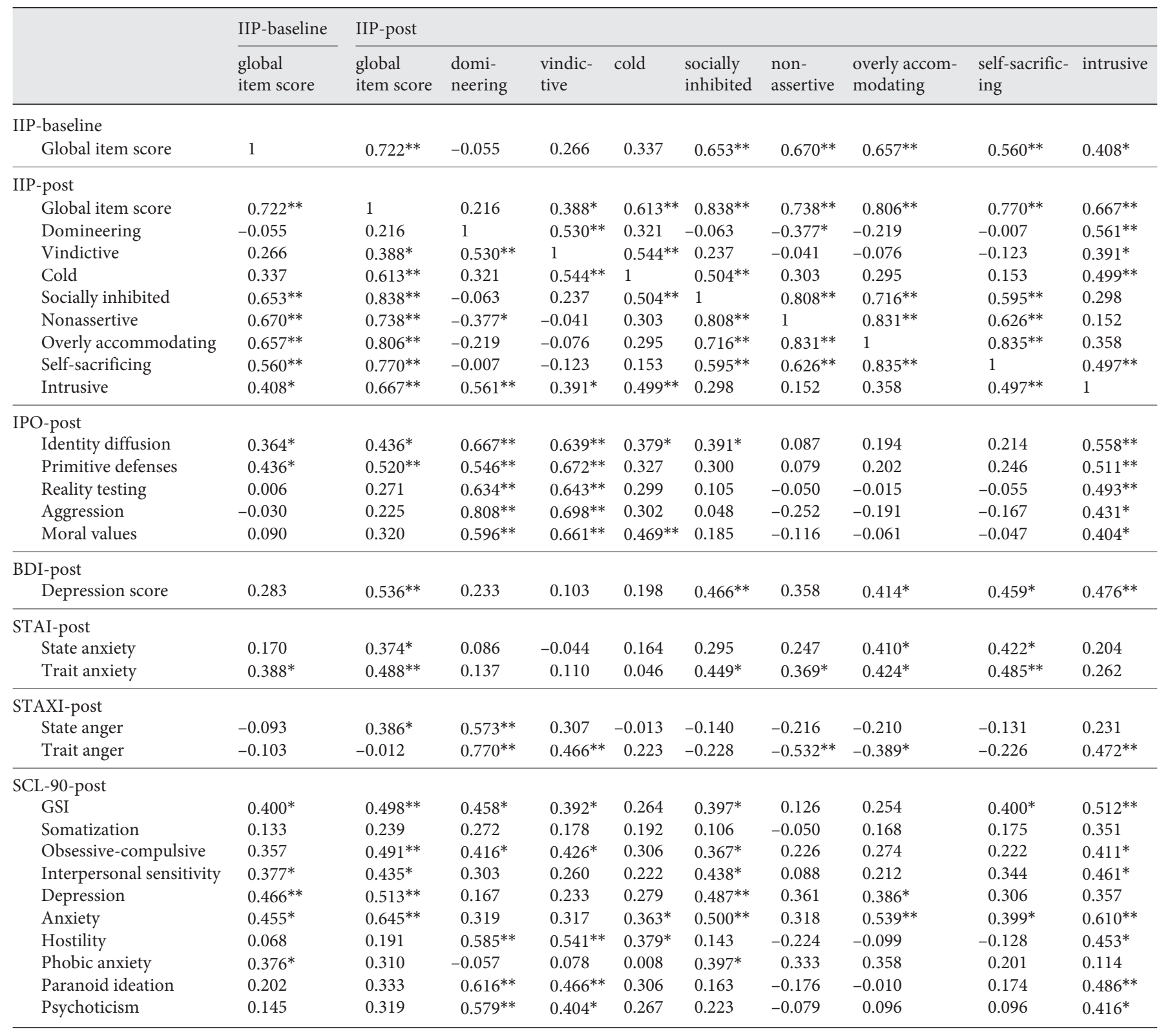

${ }^{*} \mathrm{p}<0.05 ;{ }^{* *} \mathrm{p}<0.01$

was a significant change in identity diffusion, depression, and state anger. Effect sizes ranged from small to medium. As shown in figure 1, there was a reduction in all interpersonal subscales after 12 weeks except in the domineering scale. The most substantial changes were found in the friendly submissive scales.

Impact of Interpersonal Problems in BPD
Correlations of the Baseline IIP Total Item Score with Posttreatment Variables

There was a significant correlation of the baseline IIP total item score with identity diffusion, primitive defenses, trait anxiety, and general symptom complaints as well as some SCL-90 subscales (table 3). Concerning IIP, all subscales except the domineering and vindictive scales correlated positively with the total item score. 


\section{Discussion}

We are the first to investigate the effects of an inpatient treatment that combines two therapeutic approaches for BPD (TFB and DBT) which have been proven effective in randomized clinical trials.

After treatment, our patients not only showed a significant decrease in identity diffusion, depression, and anger but also in almost all interpersonal scales. These results are especially interesting as persisting severe impairments in general, social, and interpersonal dysfunctions have been shown in longitudinal studies for BPD [8, 9, 46]. In the study of Choi-Kain et al. [47], demandingness and boundary violations turned out to remit quickly, while affectively oriented interpersonal features related to intolerance of loneliness persisted. In our study, only the domineering scale did not decrease after 12 weeks. Of course, it would have been even more interesting to know the changes in interpersonal subscales after 6 or 12 months. Gunderson et al. [48] found that the quality of current relationships of patients with BPD predicted the outcome at a 2-year follow-up.

Our other finding was that the baseline IIP total item score correlated positively with several posttreatment variables as well as with other borderline features (e.g. identity diffusion). This connection is to be taken into account in treatment underlining the importance of including improvement of interpersonal problems in therapy goals. The importance of interpersonal symptoms and processes for psychotherapy are acknowledged by psychodynamic [49] and behavioral therapists [50]. Longterm symptomatic ameliorations are related with interpersonal variables (quality of the relationship with partner or parents) [51]. Stepp et al. [52] found that interpersonal problems mediated the relationship between BPD and later violent behaviors. The interpersonal difficulties of BPD patients are of vital relevance in general psychiatric hospitals; hospitalized BPD patients feel hostilely repulsed by staff members and affronted by other patients [53]. Puschner et al. [54] found that interpersonal problems (measured with IIP) at the beginning of therapy are not associated with a negative treatment outcome. Amelioration of interpersonal problems (measured with IIP) seems to be correlated with definitive psychotherapy outcome [55]. The IIP-C subscale (coldness) was found to be a negative predictor in a long-term study with outpatient group therapy [56].

There are several limitations to our study, reducing the generalizability of the results. These include the limited number of participants of the study (particularly the small number of men), the lack of clear behavioral markers of change (e.g. Global Assessment of Functioning) during the treatment period, and the fact that the IIP general scale was very high in all patients. Also, we did not analyze the interrater reliability of our SCID interviews and did not include a control group. Still, two main conclusions seem possible. More psychopathology or comorbidity is not always an indicator for worse treatability. To the contrary, specific symptoms can be indicators for better prognosis, and less comorbidity can show less therapeutic effects (see also the results of Bateman and Fonagy [57]).

The results of our study regarding the reduction in interpersonal scales are congruent with prior results indicating that TFP could have specific advantages (compared to other treatments) in the interpersonal field (e.g. reflective functioning) [58] and that changes in identity diffusion, pseudo-altruistic interpersonal features (nonassertive, overly accommodating, self-sacrificing), and associated anger are possible and crucial.

Intensive and disorder-specific psychodynamic psychotherapy may have an especially favorable outcome for BPD patients with severe interpersonal problems due to the fact that TFP focuses on interpersonal difficulties.

Of course, further research is needed to confirm our findings and to clarify open questions, for example, why anger was not also associated with higher interpersonal problems and why the interpersonal domineering and cold subscales showed no decrease after treatment. Wright et al. [59] investigated the stability of interpersonal problems in BPD patients over the course of a year and found that interpersonal dysfunction on borderline pathology is stable in its severity but unstable in the style of its manifestation' (p. 1094).

Finally, the question arises whether our results are specific for BPD or could also occur for any other form of personality pathology. Although interpersonal problems are considered one of the more stable features of BPD, our results showed a significant improvement after only 12 weeks of TFP-based disorder-specific inpatient treatment.

\section{Acknowledgments}

The BABIS of the Basel University Psychiatric Hospital was supported by a research grant from the Swiss National Science Foundation (SNSF: 32003B-108462).
Dammann et al. 


\section{References}

$>1$ Lenzenweger MF, Lane MC, Loranger AW, 15 Giesen-Bloo J, van Dyck R, Spinhoven P, van Kessler RC: DSM-IV personality disorders in the National Comorbidity Survey Replication. Biol Psychiatry 2007;62:553-564.

$>2$ Trull TJ, Jahng S, Tomko RL, Wood PK, Sher KJ: Revised NESARC personality disorder diagnoses: gender, prevalence, and comorbidity with substance dependence disorders. J Pers Disord 2010;24:412-426.

$\checkmark 3$ Bouchard S, Sabourin S, Lussier Y, Villeneuve E: Relationship quality and stability in couples when one partner suffers from borderline personality disorder. J Marital Fam Ther 2009;35:446-455.

-4 Brodsky BS, Groves SA, Oquendo MA, Mann JJ, Stanley B: Interpersonal precipitants and suicide attempts in borderline personality disorder. Suicide Life Threat Behav 2006;36: 313-322.

5 Soloff PH, Fabio A: Prospective predictors of suicide attempts in borderline personality disorder at one, two, and two-to-five year follow-up. J Pers Disord 2008;22:123-134.

7 American Psychiatric Association: Diagnostic and Statistical Manual of Mental Disorders, ed. 5. Washington, APA, 2013.

7 Clarkin JF, Yeomans FE, Kernberg OF: Psychotherapy of Borderline Personality. New York, Wiley, 1999.

-8 Zanarini MC, Frankenburg FR, Reich DB, Silk KR, Hudson JI, McSweeney LB: The subsyndromal phenomenology of borderline personality disorder: a 10-year follow-up study. Am J Psychiatry 2007;164:929-935.

$>9$ Gunderson JG, Stout RL, McGlashan TH, Shea MT, Morey LC, Grilo CM, Zanarini MC, Yen S, Markowitz JC, Sanislow C, Ansell E, Pinto A, Skodol AE: Ten-year course of borderline personality disorder: psychopathology and function from the Collaborative Longitudinal Personality Disorders study. Arch Gen Psychiatry 2011;68:827-837.

10 NICE: Borderline Personality Disorder Treatment and Management. NICE Clinical Guideline 7. Leicester, British Psychological Society, 2009.

-11 Linehan MM, Schmidt H, Dimeff LA, Craft JC, Kanter J, Comtois KA: Dialectical behavior therapy for patients with borderline personality disorder and drug-dependence. Am J Addict 1999;8:279-292.

12 Bateman A, Fonagy P: Effectiveness of partial hospitalization in the treatment of borderline personality disorder: a randomized controlled trial. Am J Psychiatry 1999;156:15631569.

$>13$ Kellogg SH, Young JE: Schema therapy for borderline personality disorder. J Clin Psychol 2006;62:445-458.

$>14$ Verheul R, van den Bosch LMC, Koeter MWJ, de Ridder MAJ, Stijnen T, van den Brink W: Dialectical behavior therapy for women with borderline personality disorder: 12-month, randomised clinical trial in the Netherlands. Br J Psychiatry 2003;182:135-140. Tilburg W, Dirksen C, van Asselt T, Kremers I, Nadort M, Arntz A: Outpatient psychotherapy for borderline personality disorder: randomized trial of schema-focused therapy vs transference-focused psychotherapy. Arch Gen Psychiatry 2006;63:649-658.

16 Linehan MM, Comtois KA, Murray AM, Brown MZ, Gallop RJ, Heard HL, Korslund KE, Tutek DA, Reynolds SK, Lindenboim N: Two-year randomized controlled trial and follow-up of dialectical behavior therapy vs therapy by experts for suicidal behaviors and borderline personality disorder. Arch Gen Psychiatry 2006;63:757-766.

17 Clarkin JF, Levy KN, Lenzenweger MF, Kernberg OF: Evaluating three treatments of borderline personality disorder: a multiwave study. Am J Psychiatry 2007;164:922-928.

18 Stoffers JM, Völlm BA, Rücker G, Timmer A, Huband N, Lieb K: Psychological therapies for people with borderline personality disorder. Cochrane Database Syst Rev 2012; 8:CD005652.

19 McMain SF, Guimond T, Streiner DL, Cardish RJ, Links PS: Dialectical behavior therapy compared with general psychiatric management for borderline personality disorder: clinical outcomes and functioning over a 2-year follow-up. Am J Psychiatry 2012;169: 650-661.

20 Bateman A, Fonagy P: Randomized controlled trial of outpatient mentalization-based treatment versus structured clinical management for borderline personality disorder. Am J Psychiatry 2009;166:1355-1364.

21 Farrell JM, Shaw IA, Webber MA: A schemafocused approach to group psychotherapy four outpatients with borderline personality disorder: a randomized controlled trial. J Behav Ther Exp Psychiatry 2009;40:317-328.

22 Blum N, St. John D, Pfohl B, Stuart S, McCormick B, Allen J, Arndt S, Black DW: Systems Training for Emotional Predictability and Problem Solving (STEPPS) for outpatients with borderline personality disorder: a randomized controlled trial and 1-year followup. Am J Psychiatry 2008;165:468-478.

23 Doering S, Hörz S, Rentrop M, Fischer-Kern M, Schuster P, Benecke C, Buchheim A, Martius P, Buchheim P: Transference-focused psychotherapy vs treatment by community psychotherapists for borderline personality disorder: a randomised controlled trial. $\mathrm{Br} \mathrm{J}$ Psychiatry 2010;96:389-395.

24 Paris J: Is hospitalization useful for suicidal patients with borderline personality disorder?

25 Krawitz R, Watson C: Borderline Personality Disorder: A Practical Guide to Treatment. Oxford, Oxford University Press, 2000.

26 Bateman AW, Tyrer P: Services for personality disorder: organisation for inclusion. Adv Psychiatr Treat 2004;10:425-433. J Pers Disord 2004;18:240-247.
27 Bohus M, Haaf B, Simms T, Limberger MF, Schmahl C, Unckel C, Lieb K, Linehan MM: Effectiveness of inpatient dialectical behavioral therapy for borderline personality disorder: a controlled trial. Behav Res Ther 2004; 42:487-499.

28 Leichsenring F, Masuhr O, Jaeger U, Rabung S, Dally A, Dümpelmann M, Fricke-Neef C, Steinert C, Streeck U: Psychoanalytic-interactional therapy versus psychodynamic therapy by experts for personality disorders: a randomized controlled efficacy-effectiveness study in Cluster B personality disorders. Psychother Psychosom 2016;85:71-80.

29 Agarwalla PA, Küchenhoff J, Sollberger D, Gremaud-Heitz D, Riemenschneider A, Walter M, Dammann G: Ist die stationäre störungsspezifische Behandlung von Borderline-Patienten einer herkömmlichen psychiatrischen/psychotherapeutischen stationären Behandlung überlegen? Swiss Arch Neurol Psychiatry 2013;164:194-205.

-30 Sollberger D, Gremaud-Heitz D, GremaudHeitz A, Küchenhoff J, Agarwalla P, Benecke C, Schwald O, Walter M, Dammann G: Change in identity diffusion and psychopathology in a specialized inpatient treatment for borderline personality disorder. Clin Psychol Psychother 2015;22:559-569.

31 Gremaud-Heitz D, Riemenschneider A, Walter M, Sollberger D, Küchenhoff J, Dammann G: Comorbid atypical depression in borderline personality disorder is common and correlated with anxiety-related psychopathology. Compr Psychiatry 2014;55:650-656.

32 Sollberger D, Gremaud-Heitz D, Riemenschneider A, Küchenhoff J, Dammann G, Walter M: Associations between identity diffusion, Axis II disorder, and psychopathology in inpatients with borderline personality disorder. Psychopathology 2012;45:15-21.

33 Clarkin JF, Yeomans FE, Kernberg O: Psychotherapy for Borderline Personality: Focusing on Object Relations. Washington, American Psychiatric Publishing, 2006.

34 Yeomans FE, Levy KN, Meehan KB: Treatment approaches for borderline personality disorder. Psychiatric Times, April 2012, pp 42-46.

35 First MB, Spitzer RL, Gibbon M, Williams JBW: Structured Clinical Interview for DSMIV Axis I Disorders, patient edition (SCIDI/P). New York, New York State Psychiatric Institute, Biometrics Research Department, 1996.

36 First M, Gibbon M, Spitzer R: Structured Clinical Interview for DSM-IV Axis II Personality Disorders (SCID-II). Washington, American Psychiatric Press, 1997.

37 Lobbestael J, Leurgans M, Arntz A: Inter-rater reliability of the Structured Clinical Interview for DSM-IV Axis I Disorders (SCID I) and Axis II Disorders (SCID II). Clin Psychol Psychother 2011;18:75-79. 
38 Horowitz LM, Strauss B, Kordy H: Inventar zur Erfassung interpersoneller Probleme, ed 2. Göttingen, Hogrefe, 2000.

39 Kernberg OF, Clarkin JF: The Inventory of Personality Organization. White Plains, New York Hospital-Cornell Medical Center, 1995.

40 Dammann G, Smole-Lindinger S, Buchheim P: IPO - Inventar der Persönlichkeitsorganisation; in Brähler E, Schumacher J, Strauss B (eds): Diagnostische Verfahren in der Psychotherapie. Göttingen, Hogrefe, 2002, pp 217-221.

-41 Lenzenweger MF, Clarkin JF, Kernberg OF, Foelsch PA: The Inventory of Personality Organization: psychometric properties, factorial composition, and criterion relations with affect, aggressive dyscontrol, psychosis proneness, and self-domains in a nonclinical sample. Psychol Assess 2001;13:577-591.

42 Franke G: Die Symptom-Checkliste von Derogatis - deutsche Version (SCL90-R). Göttingen, Beltz, 1995.

43 Hautzinger M, Bailer M, Worrall H, Keller F: Beck-Depressions-Inventar (BDI). Testhandbuch, ed 3. Bern, Huber, 2000.

44 Laux L, Glanzmann P, Schaffner P, Spielberger C: Das State-Trait-Angstinventar: STAI. Weinheim, Beltz, 1981.

45 Schwenkmezger P, Hodapp V, Spielberger CD: Das State-Trait-Ärgerausdrucks-Inventar STAXI Handbuch. Bern, Huber, 1992.

46 Zanarini MC, Frankenburg FR, Reich DB, Fitzmaurice GM: Attainment and stability of sustained symptomatic remission and recovery among borderline patients and Axis II comparison subjects : a 16-year prospective follow-up study. Am J Psychiatry 2012;169: 476-483.

47 Choi-Kain LW, Zanarini MC, Frankenburg FR, Fitzmaurice GM, Reich DB: A longitudinal study of the 10-year course of interpersonal features in borderline personality disorder. J Pers Disord 2010;24:365-376.

48 Gunderson JG, Daversa MT, Grilo CM, McGlashan TH, Zanarini MC, Shea MT, Skodol AE, Yen S, Sanislow CA, Bender DS, Dyck IR, Morey LC, Stout RL: Predictors of 2-year outcome for patients with borderline personality disorder. Am J Psychiatry 2006;163: 822-826.

49 Bateman A, Fonagy P: Treatment of borderline personality disorder with psychoanalytically oriented partial hospitalization: an 18-month follow-up. Am J Psychiatry 2001; 158:36-42.

50 Lejuez CW, Daughters SB, Nowak JA, Lynch T, Rosenthal MZ, Stieglitz R, Bohus M: Examining the inventory of interpersonal problems as a tool for conducting analogue studies of mechanisms underlying borderline personality disorder. J Behav Ther Exp Psychiatry 2003;34:313-324.

-51 Zanarini MC, Frankenburg FR, Hennen J, Reich DB, Silk KR: Psychosocial functioning of borderline patients and axis II comparison subjects followed prospectively for six years. J Pers Disord 2005;19:19-29.

52 Stepp SD, Smith TD, Morse JQ, Hallquist MN, Pilkonis PA: Prospective associations among borderline personality disorder symp- toms, interpersonal problems, and aggressive behaviors. J Interpers Violence 2012;27:103124.

53 Benjamin LS, Wonderlich SA: Social perceptions and borderline personality disorder: the relation to mood disorders. J Abnorm Psychol 1994;103:610-624.

54 Puschner B, Bauer S, Horowitz LM, Kordy H: The relationship between interpersonal problems and the helping alliance. J Clin Psychol 2005;61:415-429.

55 Ruiz MA, Pincus AL, Borkovec TD, Echemendia RJ, Castonguay LG, Ragusea SA: Validity of the inventory of interpersonal problems for predicting treatment outcome: an investigation with the Pennsylvania Practice Research Network. J Pers Assess 2004;83:213222.

56 Lorentzen S, Høglend P: Predictors of change during long-term analytic group psychotherapy. Psychother Psychosom 2004;73:25-35.

57 Bateman A, Fonagy P: Impact of clinical severity on outcomes of mentalisation-based treatment for borderline personality disorder. Br J Psychiatry 2013;203:221-227.

58 Levy KN, Clarkin JF, Yeomans FE, Scott LN, Wasserman RH, Kernberg OF: The mechanisms of change in the treatment of borderline personality disorder with transference focused psychotherapy. J Clin Psychol 2006;62: 481-501.

59 Wright AGC, Hallquist MN, Beeney JE, Pilkonis PA: Borderline personality pathology and the stability of interpersonal problems. J Abnorm Psychol 2013;122:1094-1100. 